NASA/TM-2004-213059

\title{
A Subsonic Aircraft Design Optimization With Neural Network and Regression Approximators
}

Surya N. Patnaik

Ohio Aerospace Institute, Brook Park, Ohio

Rula M. Coroneos, James D. Guptill, Dale A. Hopkins, and William J. Haller Glenn Research Center, Cleveland, Ohio 
Since its founding, NASA has been dedicated to the advancement of aeronautics and space science. The NASA Scientific and Technical Information (STI) Program Office plays a key part in helping NASA maintain this important role.

The NASA STI Program Office is operated by Langley Research Center, the Lead Center for NASA's scientific and technical information. The NASA STI Program Office provides access to the NASA STI Database, the largest collection of aeronautical and space science STI in the world. The Program Office is also NASA's institutional mechanism for disseminating the results of its research and development activities. These results are published by NASA in the NASA STI Report Series, which includes the following report types:

- $\quad$ TECHNICAL PUBLICATION. Reports of completed research or a major significant phase of research that present the results of NASA programs and include extensive data or theoretical analysis. Includes compilations of significant scientific and technical data and information deemed to be of continuing reference value. NASA's counterpart of peerreviewed formal professional papers but has less stringent limitations on manuscript length and extent of graphic presentations.

- TECHNICAL MEMORANDUM. Scientific and technical findings that are preliminary or of specialized interest, e.g., quick release reports, working papers, and bibliographies that contain minimal annotation. Does not contain extensive analysis.

- CONTRACTOR REPORT. Scientific and technical findings by NASA-sponsored contractors and grantees.
- CONFERENCE PUBLICATION. Collected papers from scientific and technical conferences, symposia, seminars, or other meetings sponsored or cosponsored by NASA.

- SPECIAL PUBLICATION. Scientific, technical, or historical information from NASA programs, projects, and missions, often concerned with subjects having substantial public interest.

- TECHNICAL TRANSLATION. Englishlanguage translations of foreign scientific and technical material pertinent to NASA's mission.

Specialized services that complement the STI Program Office's diverse offerings include creating custom thesauri, building customized databases, organizing and publishing research results ... even providing videos.

For more information about the NASA STI Program Office, see the following:

- Access the NASA STI Program Home Page at http://www.sti.nasa.gov

- E-mail your question via the Internet to help@sti.nasa.gov

- Fax your question to the NASA Access Help Desk at 301-621-0134

- Telephone the NASA Access Help Desk at 301-621-0390

- Write to:

NASA Access Help Desk

NASA Center for AeroSpace Information 7121 Standard Drive

Hanover, MD 21076 
NASA/TM-2004-213059

AIAA-2004-4606

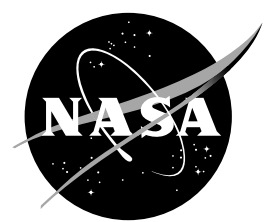

\section{A Subsonic Aircraft Design Optimization With Neural Network and Regression Approximators}

Surya N. Patnaik

Ohio Aerospace Institute, Brook Park, Ohio

Rula M. Coroneos, James D. Guptill, Dale A. Hopkins, and William J. Haller Glenn Research Center, Cleveland, Ohio

Prepared for the

10th Multidisciplinary Analysis and Optimization Conference cosponsored by the American Institute of Aeronautics and Astronautics and the International Society for Structural and Multidisciplinary Optimization Albany, New York, August 30-September 1, 2004

National Aeronautics and

Space Administration

Glenn Research Center 
This report is a formal draft or working paper, intended to solicit comments and ideas from a technical peer group.

This report contains preliminary findings, subject to revision as analysis proceeds.

This report is a preprint of a paper intended for presentation at a conference. Because of changes that may be made before formal publication, this preprint is made available with the understanding that it will not be cited or reproduced without the permission of the author.

Trade names or manufacturers' names are used in this report for identification only. This usage does not constitute an official endorsement, either expressed or implied, by the National Aeronautics and Space Administration.

This work was sponsored by the Low Emissions Alternative Power Project of the Vehicle Systems Program at the NASA Glenn Research Center.

Available from

NASA Center for Aerospace Information 7121 Standard Drive

Hanover, MD 21076
National Technical Information Service 5285 Port Royal Road Springfield, VA 22100 


\title{
A Subsonic Aircraft Design Optimization With Neural Network and Regression Approximators
}

\author{
Surya N. Patnaik ${ }^{*}$ \\ Ohio Aerospace Institute \\ Brook Park, Ohio 44142 \\ Rula M. Coroneos, James D. Guptill, Dale A. Hopkins, and William J. Haller \\ National Aeronautics and Space Administration \\ Glenn Research Center \\ Cleveland, Ohio 44135
}

\begin{abstract}
The Flight-Optimization-System (FLOPS) code encountered difficulty in analyzing a subsonic aircraft. The limitation made the design optimization problematic. The deficiencies have been alleviated through use of neural network and regression approximations. The insight gained from using the approximators is discussed in this paper. The FLOPS code is reviewed. Analysis models are developed and validated for each approximator. The regression method appears to hug the data points, while the neural network approximation follows a mean path. For an analysis cycle, the approximate model required milliseconds of central processing unit (CPU) time versus seconds by the FLOPS code. Performance of the approximators was satisfactory for aircraft analysis. A design optimization capability has been created by coupling the derived analyzers to the optimization test bed CometBoards. The approximators were efficient reanalysis tools in the aircraft design optimization. Instability encountered in the FLOPS analyzer was eliminated. The convergence characteristics were improved for the design optimization. The CPU time required to calculate the optimum solution, measured in hours with the FLOPS code was reduced to minutes with the neural network approximation and to seconds with the regression method. Generation of the approximators required the manipulation of a very large quantity of data. Design sensitivity with respect to the bounds of aircraft constraints is easily generated.
\end{abstract}

\section{Nomenclature}

$n \quad$ number of design variable, number of basis functions

Obj merit function

$R \quad$ number of kernel functions

w weight factor

$x \quad$ design variables

y functional approximation

$\nabla y \quad$ gradient matrix

$\beta \quad$ regression coefficients

$\varphi \quad$ kernel function

$\tau \quad$ threshold parameter

\section{Subscripts/Superscripts}

$\begin{array}{ll}i, j, k & \text { regression indices } \\ k & k^{\text {th }} \text { merit function } \\ \ell & l^{\text {th }} \text { design variable, lower bound } \\ r i & i^{\text {th }} \text { basis function for the } r^{\text {th }} \text { kernel }\end{array}$

*NASA Resident Research Associate at Glenn Research Center. 
CometBoards comparative evaluation test bed of optimization and analysis routines for the design of structures

$\begin{array}{ll}\text { CPU } & \text { central processing unit } \\ \text { DV } & \text { design variable } \\ \text { FD } & \text { method of feasible directions } \\ \text { FLOPS } & \text { Flight Optimization System } \\ \text { IFM } & \text { Integrated Force Method } \\ \text { I/O } & \text { input/output pairs } \\ \text { NEPP } & \text { NASA Engine Performance Program } \\ \text { NLPQ } & \text { nonlinear quadratic programming algorithm } \\ \text { NN } & \text { neural network } \\ \text { OPR } & \text { overall pressure ratio } \\ \text { SLP } & \text { sequential linear programming }\end{array}$

\section{Introduction}

The Flight Optimization System (FLOPS ${ }^{1}$ ) of NASA Langley Research Center is a standard aircraft analyzer. The FLOPS code combines multiple disciplines from aerodynamics and engine cycle analysis to mission performance. The code uses data tables for internal calculations. A brief description of the FLOPS code is given in Appendix 1. For a subsonic aircraft problem the code became unstable for some design points. The analysis limitation propagated into design optimization, and it encountered convergence difficulty. The anomalous design points resided in the vicinity of the optimum solution. These designs cannot be segregated prior to the optimization calculations. The aircraft problem appears to be a good candidate for the application of approximation techniques.

Two competing approximation techniques: neural network (NN) and regression methods are investigated to overcome the deficiency. The regression method uses a set of basis functions and provides both function and gradient information. NN approximation also uses a variety of kernel functions and produces the same two pieces of information. Both methods have been applied successfully for a variety of multidisciplinary applications. ${ }^{2-4}$ The approximate methods are developed using a set of high-fidelity training pairs and selected basis functions. The approximate models are validated for use as an alternate reanalysis tool for the subsonic aircraft analysis and design optimization.

Design optimization of the subsonic aircraft is obtained via the CometBoards ${ }^{5-6}$ test bed of NASA Glenn Research Center. CometBoards has been successfully used to solve a number of problems: structural design of space station components, ${ }^{7}$ the design of nozzle components for air-breathing engines, ${ }^{2}$ design of supersonic aircraft, ${ }^{3}$ mixed flow turbofan engines, ${ }^{8}$ and wave rotor concepts in jet engines. ${ }^{9}$ The regression method and neural-networkbased aircraft analysis tools have been incorporated into CometBoards. The optimum solution of the subsonic aircraft can be obtained using any one of the three analysis methods: the FLOPS code, NN, and regression method analyzers. The design capability is also used to calculate sensitivity with respect to the bounds on aircraft constraints; for example, the takeoff and landing field lengths.

This paper examines the performance of different analysis methods in design of a subsonic aircraft. Optimal solutions calculated by three different methods are compared. The efficiency in analysis and design is examined by comparing the central processing unit (CPU) time to solution. The paper is organized in 11 sections: the subsonic aircraft design optimization problem, the FLOPS aircraft analyzer, the CometBoards design optimization test bed, justification for use of approximate methods, regression method, NN technique, training approximate analyzers, performance of approximators for analysis and design optimization, design sensitivity analysis, positivity constraints, and conclusions.

\section{Subsonic Aircraft Design Optimization Problem}

The subsonic aircraft is powered by two high-bypass-ratio engines with a nominal thrust of about $48925 \mathrm{lbf}$. The aircraft is to carry 200 passengers and an eight-member crew, fly at a cruise speed of 0.8 Mach over a range of $2500 \mathrm{n} \mathrm{mi}$. The objective of the optimization is to determine the airframe-engine design combination that will meet specified constraints and minimize the gross takeoff weight. A good match between airframe and engine is achieved by combining the airframe variables with engine parameters. Nine active variables, listed in Table 1 , were selected. There are four airframe design variables: wing aspect ratio $\mathrm{DV}_{1}$, wing area $\mathrm{DV}_{3}$, sweep angle $\mathrm{DV}_{4}$, and thickness to chord ratio $D V_{5}$. The five engine design parameters are engine thrust $D_{2}$, the turbine inlet temperature $D_{6}$, the overall pressure ratio $\mathrm{DV}_{7}$, the bypass ratio $\mathrm{DV}_{8}$, and the fan pressure ratio $\mathrm{DV}_{9}$. Constraints are as follows: the 
Table 1. Design variables and constraints of the subsonic aircraft

\begin{tabular}{|c|c|}
\hline Design variables & Constraints \\
\hline $\mathrm{DV}_{1}$. Wing aspect ratio, $(\mathrm{EAR})$ & $g_{1}$. Landing approach velocity, (VAPP) \\
\hline $\mathrm{DV}_{2}$. Engine thrust, (ETHRUST) & $g_{2 .}$ Takeoff field length, (FAROF) \\
\hline $\mathrm{DV}_{3}$. Wing area, $(\mathrm{ESW})$ & $g_{3}$. Landing field length, (FARLD) \\
\hline $\mathrm{DV}_{4}$. Quarter chord sweep angle, (ESWEEP) & $g_{4}$. Missed approach gradient thrust, (AMFOR) \\
\hline $\mathrm{DV}_{5}$. Thickness to chord ratio, (ETCA) & $g_{5}$. Second segment climb thrust, (SSFOR) \\
\hline $\mathrm{DV}_{6}$. Turbine inlet temperature, (EETIT) & $g_{6}$. Compressor discharge temperature, (CDT) \\
\hline $\mathrm{DV}_{7 .}$ Overall pressure ratio, (EEOPR) & $g_{7}$. Excess fuel capacity, (EXFUE) \\
\hline \multicolumn{2}{|l|}{$\mathrm{DV}_{8}$. Bypass ratio, (EEBPR) } \\
\hline \multicolumn{2}{|l|}{$\mathrm{DV}_{9}$. Fan pressure ratio, (EEFPR) } \\
\hline Variables not used but can be considered include & Constraints not used but can be considered include \\
\hline $\mathrm{DV}_{\mathrm{a}}$. Taper ratio of wing, (ETR) & $g_{\mathrm{a} .}$ Range of aircraft, (RANGE) \\
\hline $\mathrm{DV}_{\mathrm{b}}$. Cruise Mach number, (EVCMN) & $g_{\mathrm{b}}$. Specific thrust, (ST) \\
\hline $\mathrm{DV}_{\mathrm{c}}$. Cruise altitude, $(\mathrm{ECH})$ & $g_{\mathrm{c} .}$ Specific fuel consumption, (SFC) \\
\hline $\mathrm{DV}_{\mathrm{d}}$. Engine throttle ratio, (EETTR) & $g_{\mathrm{d} \cdot}$ Compressor discharge pressure, (CDP) \\
\hline
\end{tabular}

landing velocity $g_{1}$ is not to exceed 125 knots. Field lengths for takeoff $g_{2}$ and landing $g_{3}$ are not to exceed $6000 \mathrm{ft}$. Missed approach gradient thrust $g_{4}$ and second segment climb thrust $g_{5}$ are required to be positive. Compressor discharge temperature $g_{6}$ should not exceed $1460{ }^{\circ} \mathrm{R}$. Excess fuel $g_{7}$ should be positive. Constraints $g_{1}, g_{2}, g_{3}$, and $g_{6}$ restrict the landing approach velocity, takeoff field length, landing field length, and compressor discharge pressure, respectively, to not exceed their upper bounds. The $g_{4}, g_{5}$, and $g_{7}$ constraints, scaled with respect to 101000 , 100 000, and $5000 \mathrm{lbf}$, respectively, restrict the variables to be positive. These are referred to as the positivity constraints.

The FLOPS code has a provision to use a composite merit function that can be expressed as

$$
O b j=\sum_{k=1}^{7} w_{k} \beta_{k}
$$

Here, Obj represents the merit function, $w_{k}$ represents the $k$ th weight factor, and the parameter $\beta_{k}$ can be selected from the following list:

(1) Gross takeoff weight of the aircraft

(2) Mission fuel

(3) The product of the Mach number and the ratio of lift-to-drag

(4) Range

(5) Cost

(6) Specific fuel consumption

(7) $\mathrm{NO}_{\mathrm{x}}$ emissions

For the subsonic problem, the gross takeoff weight is selected as the merit function by setting $w_{1}=1.0$, and the other weight factors to zero. The objective of the optimization study is to determine the optimum gross takeoff weight of the aircraft for the nine design variables and the seven behavior constraints listed in Table 1. Optimum solution is also calculated for the aircraft to operate on shorter and longer runways in the 4500 to $7500 \mathrm{ft}$ range. This exercise is referred to as sensitivity analysis. 


\section{FLOPS: An Aircraft Analyzer}

The FLOPS code calculates the performance parameters for subsonic and supersonic aircraft generating the constraints and merit function required for design optimization. The code synthesizes eight disciplines: weight estimation, aerodynamic analysis, ${ }^{10,11}$ engine cycle analysis, ${ }^{12-14}$ propulsion data interpolation, mission performance, airfield length requirements for takeoff and landing, noise footprint calculations, ${ }^{15}$ and cost estimation. ${ }^{16-21}$ The FORTRAN code has 11 modules with over 42000 statements. The subsonic aircraft problem required several input/output ( $\mathrm{I} / \mathrm{O}$ ) files. A brief description of the code is given in Appendix 1. Numerical data tables (or table lookups) used in the code can abruptly interrupt the calculations. Approximate methods can alleviate such limitations of the FLOPS code.

\section{CometBoards: A Design Optimization Test Bed}

The research to compare different optimization algorithms and alternate analysis methods for structural design applications has grown into a multidisciplinary design test bed that is still referred to by its original acronym, CometBoards, which stands for comparative evaluation test bed of optimization and analysis routines for the design of structures. The modular organization of CometBoards, shown in Fig. 1, allows innovative methods (or computer codes) to be tested quickly through its soft coupling feature. Optimizers and analyzers are two important modules of CometBoards. The optimizer module includes a number of algorithms:

The fully utilized design ${ }^{22}$

Optimality criteria methods ${ }^{22}$

The method of feasible directions ${ }^{23}$

The modified method of feasible directions ${ }^{24}$

Three different sequential quadratic programming techniques ${ }^{25-27}$

The Sequential Unconstrained Minimizations Technique ${ }^{28}$

Sequential linear programming ${ }^{23}$

A reduced gradient method ${ }^{29}$

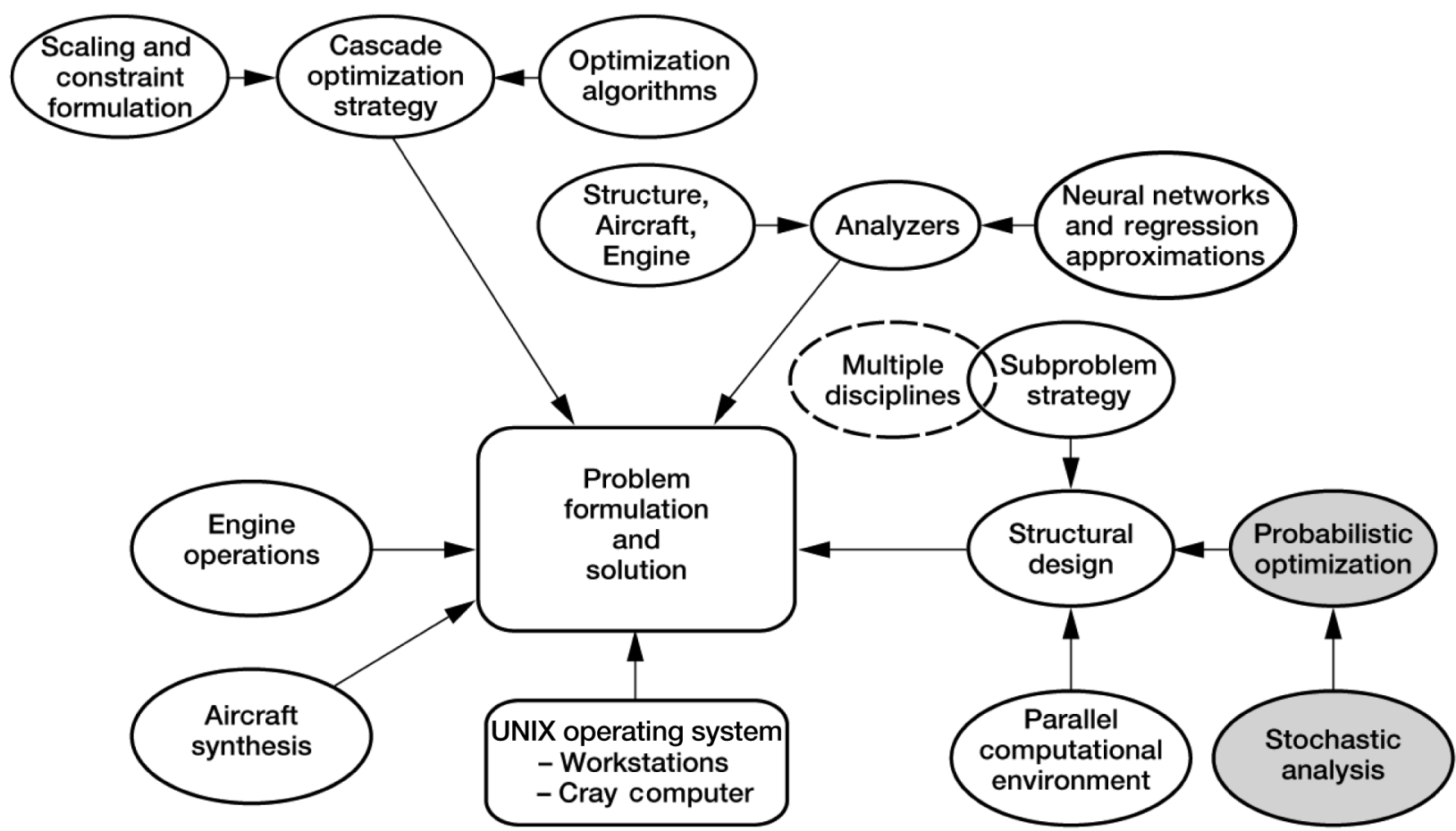

Figure 1. Organization of CometBoards. 
Likewise, the analyzer module includes

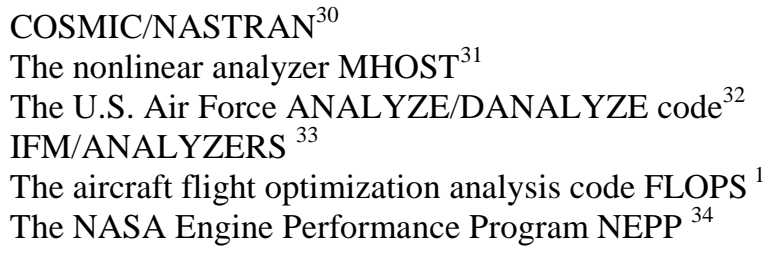

Some of the other unique features of CometBoards are

A multiple optimizer cascade strategy ${ }^{8}$

Design variable and constraint formulations

A global scaling strategy

Analysis and sensitivity approximations through regression and NNs

Substructure optimization on sequential as well as parallel computational platforms ${ }^{35}$

CometBoards has provisions to accommodate up to 10 different disciplines, each of which can have a maximum of 5 subproblems. The test bed can optimize a large system, which can be defined in as many as 50 different subproblems. Alternatively, a component of a large system can be optimized. The design test bed has been successfully used to solve a number of multidisciplinary problems. The CometBoards test bed has over 50 numerical examples. It is written in FORTRAN 77, except for the NN code Cometnet, ${ }^{36}$ which is written in the $\mathrm{C}++$ language. The $\mathrm{C}++$ code is integrated into the CometBoards FORTRAN code through soft-coupling. Soft-coupling is achieved by first generating an executable file from the Cometnet $\mathrm{C}++$ source code; then Cometnet is invoked from CometBoards through a system call. Information is exchanged between the two programs through data files. CometBoards is available on UNIX-based SGI and Sun workstations. CometBoards is continuously being improved to increase its reliability and robustness for optimization at system as well as at component levels. Stochastic calculations are being implemented into CometBoards. This paper emphasizes the approximation module of CometBoards, which includes regression method and $\mathrm{NN}$ approximations for the design optimization of the subsonic aircraft.

\section{Justification for Use of Approximate Methods}

The difficulty encountered in the FLOPS code is illustrated by generating its response for a set of design points that lie in the vicinity of the optimum solution. The FLOPS code is run for three sets of analysis data that are created by a pseudo-random perturbation about a base design within prescribed upper and lower bounds as shown in Table 2. The design space spread is about 10 percent of the base design on each side. The first set of data is referred to as "small-model," and it contains 1200 design points. The "standard-model" and the "large-model" contain 2400 and 4800 points, respectively. Each set of the nine design variables and the seven response variables (associated with design constraints) constitutes one I/O pair (which is also used to train the approximate methods). The success rate of the FLOPS analyzer is given in Table 3. The rate of success was about 80 percent for each model. For the

Table 2. Base design bounds

\begin{tabular}{|c|c|c|c|}
\hline Design variables & Lower bound & Initial design & Upper bound \\
\hline Wing aspect ratio $\left(\mathrm{DV}_{1}\right)$ & 7.340 & 8.500 & 8.810 \\
\hline Engine thrust $\left(\mathrm{DV}_{2}\right), \mathrm{lb}$ & 28000 & 31500 & 34200 \\
\hline Wing area $\left(\mathrm{DV}_{3}\right), \mathrm{ft}^{2}$ & 1830 & 2000 & 2200 \\
\hline Quarter chord sweep angle $\left(\mathrm{DV}_{4}\right)$, deg & 16.0 & 18.5 & 21 \\
\hline Thickness to chord ratio $\left(\mathrm{DV}_{5}\right)$ & 0.088 & 0.095 & 0.0997 \\
\hline Turbine inlet temperature ${ }^{*}\left(\mathrm{DV}_{6}\right),{ }^{\circ} \mathrm{R}$ & 2950 & 3000 & 3100 \\
\hline Overall pressure ratio ${ }^{*}\left(\mathrm{DV}_{7}\right)$ & 38 & 40 & 40.50 \\
\hline Bypass ratio ${ }^{*}\left(\mathrm{DV}_{8}\right)$ & 5 & 6 & 6.10 \\
\hline Fan pressure ratio* $\left(\mathrm{DV}_{9}\right)$ & 1.8 & 1.85 & 2 \\
\hline
\end{tabular}

${ }^{*}$ Redundancy in these design variables may cause instability in the subsonic aircraft calculations. 
Table 3. Success rate of the FLOPS analyzer for the subsonic aircraft

\begin{tabular}{llll}
\hline \multicolumn{1}{c}{ I/O Pairs } & \multicolumn{1}{c}{ Small } & \multicolumn{1}{c}{ Standard } & Large \\
\hline Total I/O pairs-FLOPS & 1200 & 2400 & 4800 \\
Usable I/O & 991 & 1943 & 3880 \\
Success rate, percent & 83 & 81 & 81 \\
Bad I/O & $209(17.42 \%)$ & $457(19.04 \%)$ & $920(19.17 \%)$ \\
Saturated at 250 kip for aircraft weight & 204 & 448 & 891 \\
Code aborted & 3 & 7 & 16 \\
Negative million for engine thrust & 1 & 1 & 6 \\
Zero thrust & 1 & 1 & 7 \\
Used for training & 900 & 1800 & 3600 \\
Used for validation & 91 & 143 & 280 \\
\hline
\end{tabular}

standard model only 1943 usable I/O pairs could be generated out of the 2400 requested design points. The aircraft weight saturated at a quarter million pound-force for 448 design points. The code aborted for seven designs. Turbine entry temperature reached a million degrees for one case and a zero thrust condition was encountered for another case. The $250000 \mathrm{lbf}$ weight, $10^{6}{ }^{\circ} \mathrm{R}$ temperature, and zero thrust condition are either reference or flagged value of the unsized aircraft. The response for the small and large model was similar with minor deviations.

The design space of an aircraft optimization problem is distorted because both design variables and constraints vary over a wide range. For example, an engine thrust design variable measured in kilo pound-force is immensely different than the bypass ratio, which is a small dimensionless number. Likewise, a landing velocity constraint in knots and a field length limitation in thousands of feet differ both in magnitude and in units of measure. In the design optimization test bed CometBoards the effect of distortion is reduced by scaling the merit function,

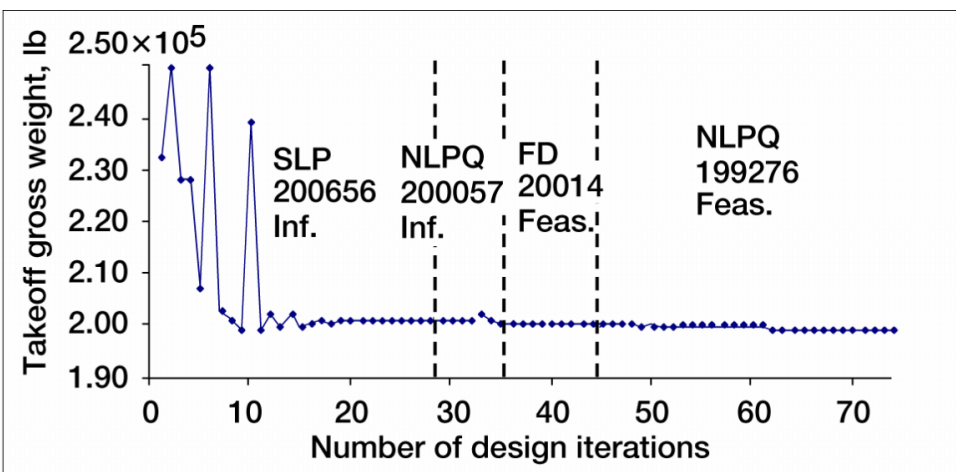

(a) IBM workstation

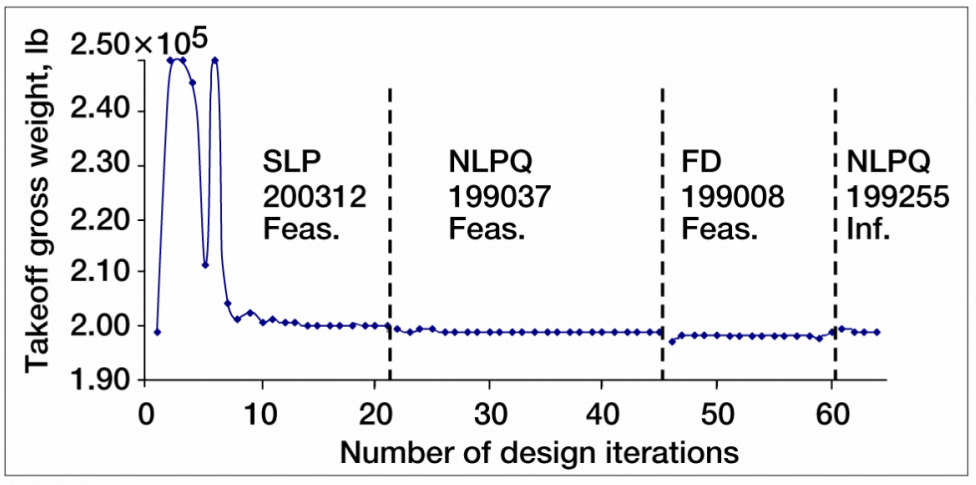

(b) SGI workstation

Figure 2. Convergence history for the subsonic aircraft with FLOPS analyzer and a cascade strategy in an IBM and SGI workstations.

design variables, and constraints such that their normalized magnitudes are around unity.

Design optimization of the subsonic aircraft was attempted using the combined CometBoards-FLOPS code. None of the one dozen individual optimization algorithms available in the CometBoards test bed could successfully solve the problem. A better solution could be obtained when a cascade strategy was employed. The generation of an optimum solution required manual intervention, restarts, as well as a change of the initial designs and bounds. A four-optimizer cascade was employed to solve the problem: sequential linear programming (SLP), followed by a nonlinear quadratic programming algorithm (NLPQ), then method of feasible directions (FD), and finally NLPQ.

Solutions generated on IBM and SGI workstations are depicted in Fig. 2. The cascade algorithm converged to $199276 \mathrm{lbf}$ for the aircraft weight. The same cascade algorithm encountered difficulty on an SGI workstation when it was initiated from a different initial design. Likewise a slightly different cascade exhibited a contrary move. The problem was solved on the SGI workstation with the original cascade algorithm when the design bounds were 
Table 4. Summary of optimum design solutions with positivity constraints

\begin{tabular}{|c|c|c|c|}
\hline & $\begin{array}{c}\text { Success } 1 \\
\text { IBM workstation }\end{array}$ & $\begin{array}{c}\text { Success } 2 \\
\text { SGI workstation }\end{array}$ & $\begin{array}{c}\text { Percent } \\
\text { variation }\end{array}$ \\
\hline Aircraft weight, lb & 199275.578 & 199254.844 & 0.010 \\
\hline \multicolumn{4}{|l|}{ Design variables: } \\
\hline Wing aspect ratio $\left(\mathrm{DV}_{1}\right)$ & 8.547 & 8.63 & -0.96 \\
\hline Engine thrust $\left(\mathrm{DV}_{2}\right), \mathrm{lb}$ & 31589.572 & 31595.923 & -0.020 \\
\hline Wing area $\left(\mathrm{DV}_{3}\right), \mathrm{ft}^{2}$ & 1897.735 & 1879.461 & 0.972 \\
\hline Quarter chord sweep angle $\left(\mathrm{DV}_{4}\right)$, deg & 15.650 & 16.411 & -4.637 \\
\hline Thickness to chord ratio $\left(\mathrm{DV}_{5}\right)$ & 0.093 & 0.093 & 0.0 \\
\hline Turbine inlet temperature $\left(\mathrm{DV}_{6}\right),{ }^{\circ} \mathrm{R}$ & 3060 & 3100 & -1.290 \\
\hline Overall pressure ratio $\left(\mathrm{DV}_{7}\right)$ & 40 & 40.188 & -0.469 \\
\hline Bypass ratio $\left(\mathrm{DV}_{8}\right)$ & 5.936 & 5.896 & 0.678 \\
\hline Fan pressure ratio $\left(\mathrm{DV}_{9}\right)$ & 1.824 & 1.80 & 1.333 \\
\hline \multicolumn{4}{|l|}{ Constraints: } \\
\hline Landing approach velocity $\left(g_{1}\right)$, kn & 119.25 & 119.72 & -0.392 \\
\hline Takeoff field length $\left(g_{2}\right), \mathrm{ft}$ & 6000 & 6042.66 & -0.706 \\
\hline Landing field length $\left(g_{3}\right), \mathrm{ft}$ & 5490 & 5514.84 & -0.450 \\
\hline Missed approach gradient thrust $\left(g_{4}\right)$, lb & 3737 & 3905.67 & -4.318 \\
\hline Second segment climb thrust $\left(g_{5}\right)$, lb & 8300 & 8548.0 & -2.901 \\
\hline Compressor discharge temperature $\left(g_{6}\right),{ }^{\circ} \mathrm{R}$ & 1423.50 & 1429.81 & -0.441 \\
\hline Excess fuel capacity $\left(g_{7}\right)$, lb & 0.2 & 0.0 & ------- \\
\hline
\end{tabular}

changed, see Fig. 2(b). The optimum designs are given in Table 4. A minor deviation is observed in the two solutions. There was only a 0.1-percent change in the aircraft weight. There was a 3-percent deviation in the engine bypass ratio design variable and 1 percent variation in the second segment climb thrust constraint. Such deviation is considered minor because the subsonic airframe engine synthesis is a difficult nonlinear multidisciplinary analysis as well as design problem. The subsonic aircraft problem appears to be a candidate for the use of approximation techniques because the FLOPS analyzer can fail for some design points, the subsonic aircraft optimization process can become tedious, and a significant reduction can be achieved in the CPU time to solution.

\section{Regression Method}

The linear regression method and NN technique are used as two competing approximators in CometBoards. The regression method uses several types of basis functions. These functions can be selected from (1) a full cubic polynomial, (2) a quadratic polynomial, (3) a linear polynomial in reciprocal variables, (4) a quadratic polynomial in reciprocal variables, and (5) combinations thereof. Consider, for example, regression analysis of an $n$-variable model with a combination of a cubic polynomial in design variables and a quadratic polynomial in reciprocal design variables. The regression function has the following explicit form:

$$
y(\vec{x})=\beta_{0}+\sum_{i=1}^{n} \beta_{i} x_{i}+\sum_{i=1}^{n} \sum_{j=i}^{n} \beta_{i j} x_{i} x_{j}+\sum_{i=1}^{n} \sum_{j=i}^{n} \sum_{k=j}^{n} \beta_{i j k} x_{i} x_{j} x_{k}+\sum_{i=1}^{n} \vec{\beta}_{i} \frac{1}{x_{1}}+\sum_{i=1}^{n} \sum_{j=i}^{n} \vec{\beta}_{i j} \frac{1}{x_{i} x_{j}}
$$

The regression coefficients $\vec{\beta}$ are determined by using the double precision general matrix linear least squares solver (DGELS) routine of the Lapack library. ${ }^{37}$ The gradient matrix of the regression function with respect to the design variables is obtained in closed form. For the example with $n$ variables, the gradient matrix for the regression function has the following form: 


$$
\nabla y=\left\{\begin{array}{c}
\frac{\partial}{\partial x_{1}} \\
\frac{\partial}{\partial x_{2}} \\
\vdots \\
\frac{\partial}{\partial x_{n}}
\end{array}\right\} y
$$

where

$$
\frac{\partial y}{\partial x_{\ell}}=\beta_{\ell}+\sum_{i=1}^{n} \beta_{i \ell} x_{i}+\beta_{\ell \ell} x_{\ell}+\sum_{i=1}^{n-1} \sum_{j=i+1}^{n} \beta_{i j \ell} x_{i} x_{j}+\sum_{i=1}^{n} \beta_{i i \ell} x_{i}^{2}+\sum_{i=1}^{n} \beta_{i \ell \ell} x_{i} x_{\ell}+\beta_{\ell \ell \ell} x_{\ell}^{2}-\frac{\beta_{\ell}}{x_{\ell}^{2}}-\frac{1}{x_{\ell}^{2}} \sum_{i=1}^{n} \beta_{i \ell} \frac{1}{x_{i}}-\frac{\beta_{\ell \ell}}{x_{\ell}^{3}}
$$

and $\beta_{i j}=\beta_{j i}$ for $i>j, \beta_{i j k}=\beta_{i k j}$ for $j>k>i$, etc.

Reanalysis and sensitivity calculations given by Eqs. (2) to (4) require trivial computation, once the regression coefficients have been obtained from a single training cycle.

\section{Neural Network Technique}

The NN approximator Cometnet is a general-purpose object-oriented library. Cometnet is soft-coupled to the CometBoards test bed. The NN capability provides both the function value and its gradient. Cometnet approximates the function and its gradient with $R$ kernel functions as follows:

$$
\begin{gathered}
y(\vec{x})=\sum_{r=1}^{R} \sum_{i=1}^{n_{r}} w_{r i} \varphi_{r i}(\vec{x}) \\
\frac{\partial y(\vec{x})}{\partial x_{\ell}}=\sum_{r=1}^{R} \sum_{i=1}^{n_{r}} w_{r i} \frac{\partial \varphi_{r i}(\vec{x})}{\partial x_{\ell}}
\end{gathered}
$$

where $y$ is the functional approximation, $\vec{x}$ is the vector of independent variables, $\varphi_{r i}$ represent $R$ kernel functions, $n_{r}$ represents the number of basis functions in a given kernel, and $w_{r i}$ are the weight factors.

Cometnet permits approximations by using different types of kernels, which include linear, reciprocal, and polynomial, as well as Cauchy and Gaussian, radial functions. A Singular Value Decomposition algorithm ${ }^{38}$ for computing the weight factors in the approximating function is used to train the network. A clustering algorithm is used to select suitable parameters for defining the radial functions. The clustering algorithm, in conjunction with an optimizer, seeks optimal values for the parameters over a range for the threshold parameter $\tau$ within its domain $(0<\tau<1)$. The mean-square error during training is reduced by increasing the threshold, which corresponds to an increase in the number of basis functions. Over-fitting is avoided with a competing complexity-based regularization algorithm. Training of the merit function and each of the constraint functions can use different basis functions.

\section{Training Approximate Analyzers}

The I/O pairs generated earlier (see Table 3) are used to train three models for the NN and regression methods. The models are referred to as small, standard, and large. The number of I/O pairs used to train and validate the models is $(900,91)$ for the small model, $(1800,143)$ for the standard model, and $(3600,280)$ for the large model. Each method has nine free variables, being the design variables given in Table 1 . Aircraft weight and the seven constraints are approximated individually. The basis functions for both approximators contain a full quadratic polynomial in the design variables (DV) along with a linear reciprocal expression in the DV. Each approximator has 
Table 5. CPU time in seconds in an SGI octane workstation

\begin{tabular}{lcccccc}
\hline & \multicolumn{3}{c}{ Regression method } & \multicolumn{3}{c}{ Neural network technique } \\
\cline { 2 - 7 } & Small & Standard & Large & Small & Standard & Large \\
\cline { 2 - 7 } Training, s & 0.2 & 0.4 & 0.8 & 59.1 & 136 & 538.8 \\
$\begin{array}{l}\text { Re-analysis, ms } \\
\text { (FLOPS = 3.1 s) }\end{array}$ & --- & --- & 0.08 & --- & --- & 2.4 \\
$\begin{array}{l}\text { Re-analysis with } \\
\quad \text { closed form gradient, ms }\end{array}$ & --- & --- & 0.14 & --- & --- & 13.5 \\
$\begin{array}{c}\text { Design optimization, s } \\
\quad(\text { percent of FLOPS solution } \\
\text { time = 2031 s) }\end{array}$ & 1.6 & 1.7 & 1.6 & 300.9 & 199.2 & 166.7 \\
& $(0.78)$ & $(0.84)$ & $(0.78)$ & $(15)$ & $(9.8)$ & $(8.2)$ \\
\hline
\end{tabular}

Table 6. Performance of the approximators during analysis

\begin{tabular}{|c|c|c|c|c|c|c|c|}
\hline \multirow[b]{2}{*}{ Response variables } & \multicolumn{4}{|c|}{$\begin{array}{l}\text { Regression method, } \\
\text { percent error }\end{array}$} & \multicolumn{3}{|c|}{$\begin{array}{l}\text { Neural network technique, } \\
\text { percent error }\end{array}$} \\
\hline & $\begin{array}{l}\text { FLOPS } \\
\text { solution }\end{array}$ & Small & Standard & Large & Small & Standard & Large \\
\hline Aircraft weight, lb & 204725.75 & 1.85 & 1.67 & 1.60 & -0.21 & -0.47 & -0.66 \\
\hline Approach velocity, kn & 112.73 & 0.91 & 0.83 & 0.80 & -1.93 & -0.09 & -2.18 \\
\hline Takeoff field length, ft & 5490.55 & 3.66 & 3.09 & 2.91 & -1.12 & -1.59 & -2.03 \\
\hline Landing field length, $\mathrm{ft}$ & 5173.08 & 0.94 & 0.88 & 0.85 & -1.94 & -2.11 & -2.21 \\
\hline Missed approach thrust, lb & 3766.80 & -14.48 & -12.82 & -12.22 & -5.76 & -3.66 & -1.91 \\
\hline Second segment climb, lb & 8516.09 & -5.29 & -4.67 & -4.45 & -2.68 & -1.91 & -1.25 \\
\hline Compressor discharge temp, ${ }^{\circ} \mathrm{R}$ & 1383.64 & -0.07 & 0.20 & 0.01 & -2.03 & -1.84 & -2.06 \\
\hline Excess fuel, lb & 4237.26 & -77.59 & -70.03 & -66.94 & 4.77 & 17.08 & 24.87 \\
\hline
\end{tabular}

64 unknown coefficients. The redundancy (ratio of I/O pair to number of coefficients) is 14, 28, and 56 for the small, standard, and large models, respectively. The values of the coefficients in NN and regression need not be the same because they are generated following different procedures. The CPU time for training, reanalysis, and design optimization on an SGI octane workstation with the irix $6.5 .19 \mathrm{~m}$ operating system and a $300 \mathrm{MHZ}$ processor is given in Table 5. The regression method required a fraction of a CPU second for training. The NN training required between 1 and 9 minutes. For a single analysis cycle, the FLOPS code required about 3 CPU seconds. This was reduced to milliseconds by the approximators. Gradient calculation is inexpensive by the approximators. For optimization the CPU time to solution by FLOPS was 34 minutes. This was reduced to less than two seconds by the regression method, while the $\mathrm{NN}$ average time was about 4 minutes. For analysis and design calculations the approximate methods are found to be efficient.

\section{Performance of Approximators for Analysis and Design Optimization}

Solutions obtained by different approximation models for a randomly selected design point $\left(\mathrm{DV}_{1}, \ldots\right.$, $\mathrm{DV}_{9}=8.9579,31607.7515,2177.9724,18.5423,0.0874,2982.4585,37.2243,5.8297,1.8295$ ) are given in Table 6. The three regression models predicted the aircraft weight with 2 percent error. It was reduced to less than 1 percent for the NN technique. For the compressor discharge temperature, the error in regression and NN methods averaged 0.1 and 2 percent, respectively. The average error in the field length constraints ranged between 1 and 3 percent for both approximators. However the error was positive for the regression method, while it was negative for the NN. The error in approach velocity was similar to field length constraints. The error was higher for the positivity constraints $g_{4}, g_{5}$, and $g_{7}$. The solution fidelity was about the same for the small, standard, and the large models.

To further assess the overall performance of the approximators the errors in the aircraft weight is calculated at 101 design points for engine thrust (in the range 28 to $35 \mathrm{kip}$ ), wing area (1800 to $2200 \mathrm{ft}^{2}$ ), and turbine inlet temperature (2900 to $\left.3100{ }^{\circ} \mathrm{R}\right)$. The mean errors and the standard deviations for the three models is given in Table 7 . 
Table 7. Percent absolute error in weight over certain design variable ranges

\begin{tabular}{|c|c|c|c|c|}
\hline & \multicolumn{2}{|c|}{ Regression } & \multicolumn{2}{|c|}{ Neural network } \\
\hline Variable, range, and model & Mean & $\begin{array}{r}\text { Standard } \\
\text { deviation }\end{array}$ & Mean & $\begin{array}{r}\text { Standard } \\
\text { deviation }\end{array}$ \\
\hline \multicolumn{5}{|l|}{ Thrust (28 to 35 kip) } \\
\hline Small & 0.90 & 0.15 & 1.05 & 0.69 \\
\hline Standard & 1.22 & 0.28 & 0.92 & 0.61 \\
\hline Large & 1.50 & 0.16 & 1.01 & 0.66 \\
\hline \multicolumn{5}{|c|}{ Turbine inlet temperature (2900 to $3100{ }^{\circ} \mathrm{R}$ ) } \\
\hline Small & 0.73 & 0.26 & 2.08 & 1.19 \\
\hline Standard & 0.81 & 0.31 & 2.09 & 1.21 \\
\hline Large & 1.10 & 0.34 & 2.11 & 1.21 \\
\hline \multicolumn{5}{|l|}{ Wing area (1800 to $\left.2200 \mathrm{ft}^{2}\right)$} \\
\hline Small & 1.16 & 0.22 & 1.30 & 1.05 \\
\hline Standard & 1.10 & 0.11 & 1.12 & 0.96 \\
\hline Large & 1.44 & 0.07 & 1.16 & 0.91 \\
\hline
\end{tabular}

Table 8. Optimum solution with original and modified positivity constraints

\begin{tabular}{lrrrr} 
& $\begin{array}{c}\text { FLOPS } \\
\text { original }\end{array}$ & $\begin{array}{c}\text { Regression } \\
\text { original }\end{array}$ & $\begin{array}{c}\text { FLOPS } \\
\text { modified }\end{array}$ & $\begin{array}{c}\text { Regression } \\
\text { modified }\end{array}$ \\
\hline Aircraft weight, lb & 199046.9 & 196965.1 & 199395.3 & 198240.8 \\
Design variables: & & & & \\
Wing aspect ratio $\left(\mathrm{DV}_{1}\right)$ & 8.6 & 8.8 & 8.8 & 8.8 \\
Engine thrust $\left(\mathrm{DV}_{2}\right), \mathrm{lb}$ & 31408.5 & 30179.5 & 32346.6 & 32181.1 \\
Wing area $\left(\mathrm{DV}_{3}\right)$, $\mathrm{ft}^{2}$ & 1899.8 & 1915.0 & 1851.3 & 1834.7 \\
Quarter chord sweep angle $\left(\mathrm{DV}_{4}\right)$, deg & 16.0 & 16.7 & 20.2 & 17.0 \\
Thickness to chord ratio $\left(\mathrm{DV}_{5}\right)$ & 0.1 & 0.1 & 0.1 & 0.1 \\
Turbine inlet temperature $\left(\mathrm{DV}_{6}\right),{ }^{\circ} \mathrm{R}$ & 3100 & 3100.0 & 3100.0 & 3094.5 \\
Overall pressure ratio, $\left(\mathrm{DV}_{7}\right)$ & 40.5 & 38.0 & 40.5 & 38.0 \\
Bypass ratio $\left.(\mathrm{DV})_{8}\right)$ & 6.1 & 5.0 & 6.1 & 5.1 \\
Fan pressure ratio $\left(\mathrm{DV} \mathrm{V}_{9}\right)$ & 1.8 & 1.8 & 1.8 & 1.8 \\
Constraints: & & & & \\
Landing approach velocity $\left(g_{1}\right), \mathrm{kn}$ & 119.0 & 117.9 & 120.7 & 120.9 \\
Takeoff field length, $\left(g_{2}\right), \mathrm{ft}$ & 6000 & 6000.0 & 5998.3 & 6000.0 \\
Landing field length $\left(g_{3}\right), \mathrm{ft}$ & 5479.4 & 5425.8 & 5562.8 & 5573.7 \\
Missed approach gradient thrust $\left(g_{4}\right), \mathrm{lb}$ & 3746.1 & 3136.1 & 5000 & 5000 \\
Second segment climb thrust $\left(g_{5}\right), \mathrm{lb}$ & 8385 & 7721 & 9619 & 9594 \\
Compressor discharge temperature $\left(g_{6}\right),{ }^{\circ} \mathrm{R}$ & 1429.0 & 1405.2 & 1428.3 & 1405.9 \\
Excess fuel capacity $\left(g_{7}\right), \mathrm{lb}$ & 0 & 2553.8 & 500 & 500
\end{tabular}

Both approximators produced about a 1-percent mean error for all three variables, except for a 2-percent error for the turbine inlet temperature by the $\mathrm{NN}$ technique. The standard deviation in error with the regression method was less than 0.3 percent. This was increased to about 1 percent with the NN technique. The error was comparable for the small, standard, and large models.

In the aircraft design optimization, the FLOPS analyzer was replaced by the approximate models without any other change. This combined code was run to obtain optimum solution for the aircraft. The combined solution is given in Table 8. CPU time to solution is given in Table 5. A convergence graph that shows the aircraft weight 


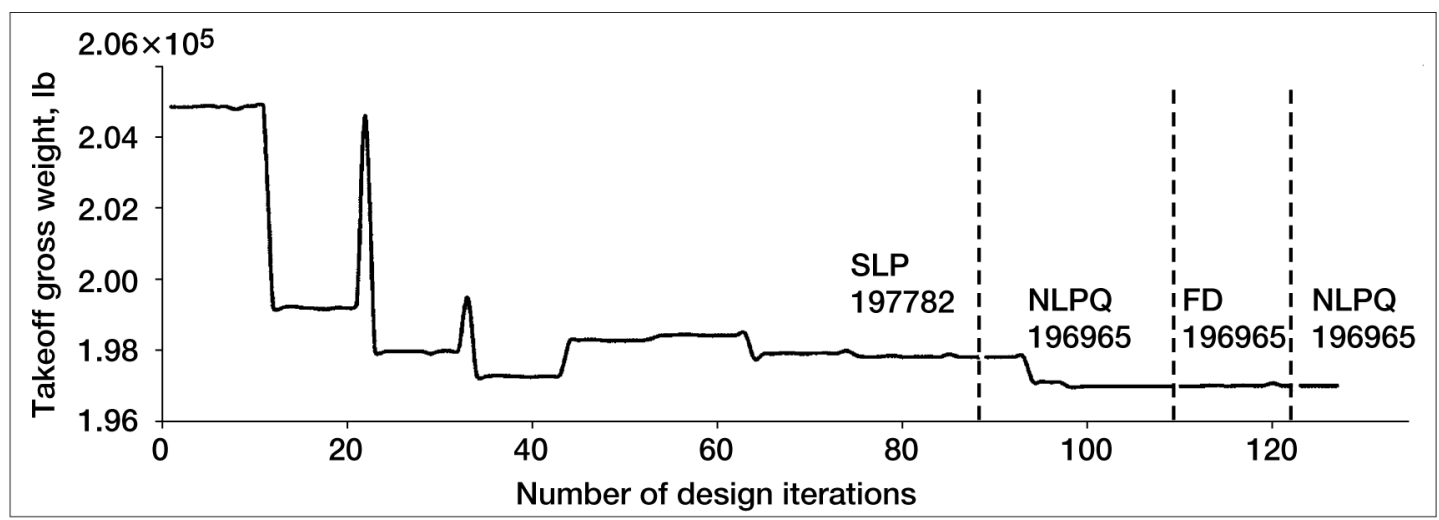

(a) Original positivity constraints.

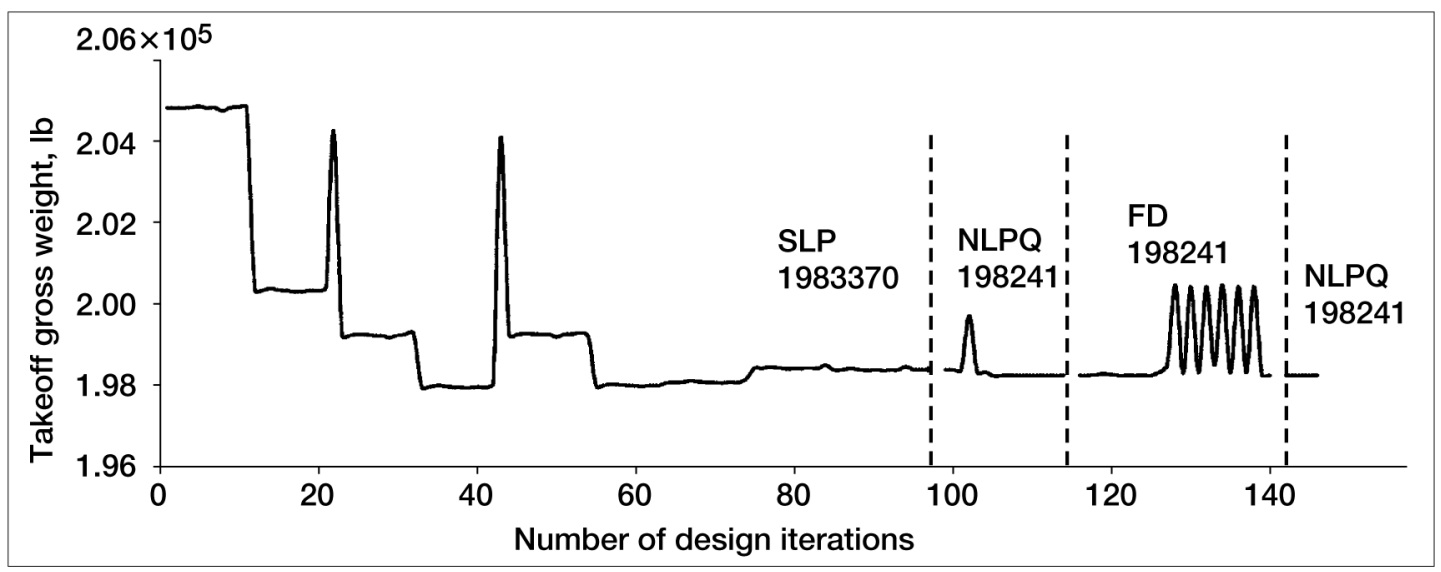

(b) Modified positivity constraints.

Figure 3. Performance of the large model with Regression method with original and modified positivity constraints.

versus iteration is depicted in Fig. 3 for the large regression model. From a comparison of this graph with Fig. 2(b), which used the FLOPS code, we observe:

1. Design with the approximator required about double the number of iterations than it did with the FLOPS code. However, the time to solution was in favor of the approximator: 1.6 CPU seconds for the regression method, versus $2031 \mathrm{~s}$ for the FLOPS code. The NN used $222 \mathrm{~s}$.

2. The convergence pattern contained oscillations for both the regression method and the FLOPS code. The amplitudes of the oscillations in the first cascade algorithm were considerably smaller for the regression method, see Figs. 2(b) and 3. However, a cascade algorithm was required for the FLOPS code as well as for the regression method.

3. The approximator exhibited 1 percent error in the optimum weight of the aircraft. For field length and approach velocity constraints the error was less than 2 percent. Error was greater for the positivity constraints, which is discussed subsequently.

\section{Design Sensitivity Analysis}

Design sensitivity was examined for the aircraft to land and takeoff on shorter and longer runways ranging from 4500 to $7500 \mathrm{ft}$ in length with $6000 \mathrm{ft}$ as the nominal value. Other parameters are retained at their nominal value. The optimum solutions are depicted in Fig. 4. Optimum aircraft weight versus the field length obtained by the three methods (FLOPS, NN, and regression) is shown in Fig. 4(a). Likewise the overall pressure ratio and second segment climb thrust are given in Figs. 4(b) and (c), respectively. The approximators exhibited less than 1 percent error in the aircraft weight. Aircraft weight is increased for shorter field length and it is decreased for longer length, as expected. 


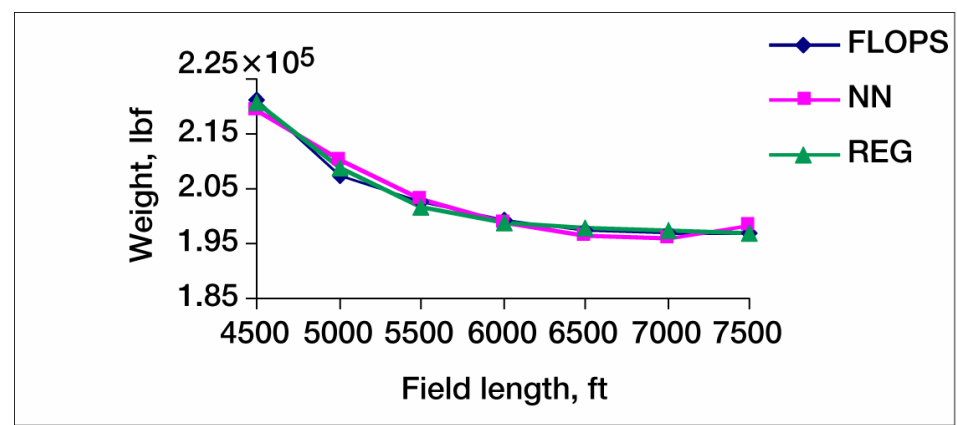

(a) Gross aircraft weight.

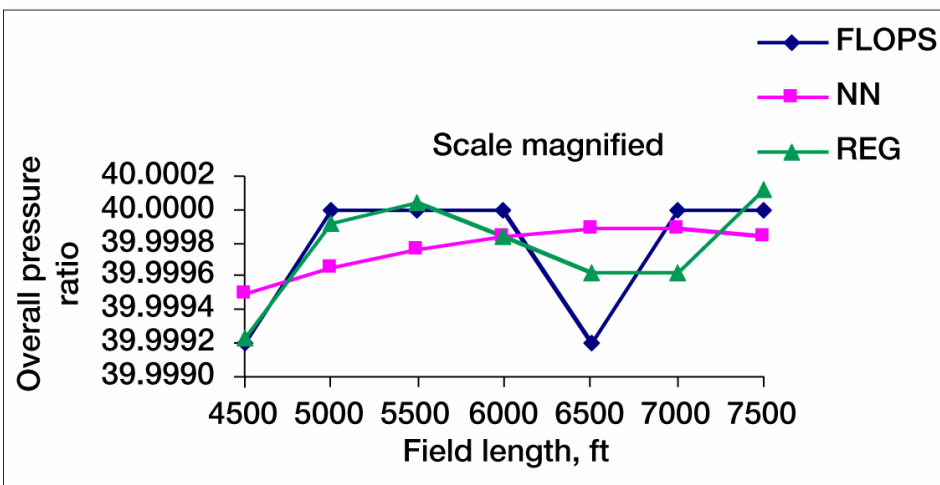

(b) Overall pressure ratio.

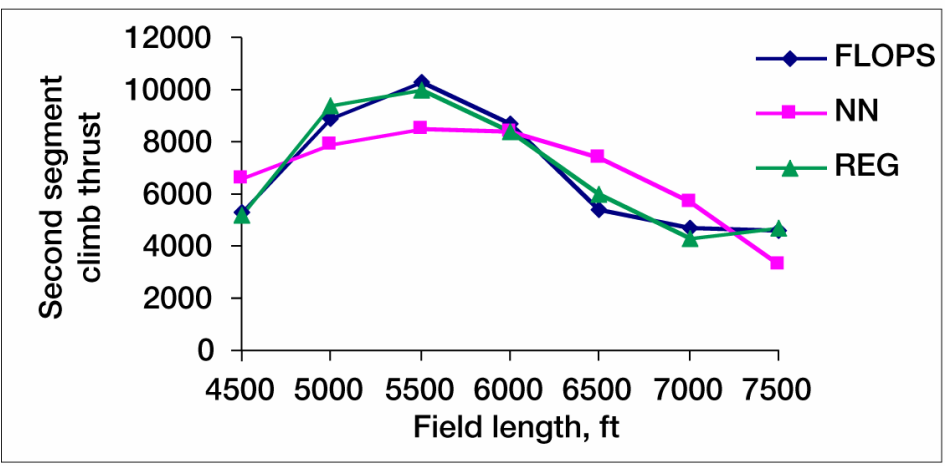

(c) Second segment climb thrust.

Figure 4. Subsonic aircraft sensitivity analysis with respect to field lengths for the small model.

0.58 percent error. The errors with the originat regression and respectively.

2. Design variables: The modified regression solution for engine thrust and turbine entry temperature exhibited 0.5 and 0.2 percent error, respectively. The quarter chord sweep angle variable exhibited the most deviation: 16.0 percent for the modified regression versus 21 percent for the original solution.

3. Constraints: There was little error in constraints between the modified regression solution and the base design. Constraints $g_{4}$ and $g_{7}$ became active for both the FLOPS and regression methods. For the $g_{5}$ constraint, the error was 0.3 percent for the modified regression case; between the original FLOPS and original regression cases, it was 13 and 20 percent, respectively.

4. Overall, the modified regression solution exhibited a closer match with the base design.

The NN and regression methods exhibited 0.34 and 0.61 percent error, respectively. Overall pressure ratio (OPR) constraint is graphed in a magnified scale in Fig. 4(b). The approximators hardly exhibit any deviation from the FLOPS solution. Observe however, the discontinuity in the OPR constraint. The regression method has path. The discontinuity will adversely effect the aircraft optimization when the FLOPS code is used. The NN should experience no limitation in design optimization. The me regression method for NN method. segment climb thrust constraint is similar to that for OPR. The regression method closely follows the constraint while $\mathrm{NN}$ takes an average path.

\section{Positivity Constraints}

Three constraints of the problem: $g_{4}$ (missed approach gradient thrust), $g_{5}$ (second segment climb thrust), and $g_{7}$ (excess fuel capacity) restrict the associated parameter to be positive. The parameters were allowed to approach zero. In a modified case the parameters are pushed away from zero, through specified lower bounds: $g^{\ell} \leq g, \quad g_{4}^{\ell}=g_{5}^{\ell}=5000 \mathrm{lbf}$ and $g_{7}^{\ell}=500$ lbf. The optimum solutions for four different situations are given in Table 8. From a comparison of the FLOPSmodified case to the base design (second to 1. Aircraft weight: The modified regression solution (see the last column in Table 8) matched the base solution with a matched the base solution with a 


\section{Conclusions}

The cascade optimization strategy solved the subsonic aircraft design optimization problem, even though restarts were required. It is preferable to restrict the behavior parameters from approaching zero values. The optimum aircraft weight calculated by the Flight Optimization System (FLOPS) analyzer and the regression method approximation matched well. The deviation in the design variables between the two analyzers was not significant. Deviation can be significant for some behavior constraints when these constraints approach zero values. Overall, the performances of the neural network and regression method were comparable. The neural network followed a mean path, while the regression method exhibited a tendency to closely follow the FLOPS solution. For a single analysis cycle the FLOPS time measured in seconds is reduced to milliseconds by the approximators. The training, validation, and solution required a small fraction of FLOPS analysis and design time. For design optimization, the central processing unit (CPU) time with the FLOPS analyzer measured in hours was reduced to minutes by the neural network, and seconds by the regression method. Generation of high-fidelity input/output pairs to train the approximators was time consuming. 



\section{Appendix \\ Organization of Flight Optimization System-FLOPS code}

The multidisciplinary FLOPS code can be used for preliminary design evaluation of aircraft concepts. The FLOPS FORTRAN code has nine modules: weights, aerodynamics, engines cycle analysis, propulsion data scaling and interpolation, mission performance, takeoff and landing, noise footprint, cost analysis, and program control. The FLOPS manual (Ref. 1) specifies preparation of input data, which follows a namelist format with default values.

The subsonic aircraft has a fuselage with a length of $152.35 \mathrm{ft}$, width of $16.44 \mathrm{ft}$, and depth of $17.00 \mathrm{ft}$. It is to carry 200 passengers with 5 stewardesses and 3 flight crewmembers. It is powered by two wing-mounted engines with a design point net thrust of $48925.0 \mathrm{lbf}$ per engine. It is a separate-flow turbofan engine with two compressor components. The weight of the engine is $9410 \mathrm{lbf}$. The baseline engine nacelle is $19.75 \mathrm{ft}$ long with an average diameter of $7.81 \mathrm{ft}$. Wing area is $2272 \mathrm{ft}^{2}$, sweep angle is $31.5^{\circ}$, taper ratio is 0.267 , and wing thickness-to-chord ratio is 0.109 .

Nominal parameters of the engine include a bypass ratio of 5 , overall pressure ratio of 29.5 , fan pressure ratio of 1.67 , compressor discharge temperature of $1460{ }^{\circ} \mathrm{R}$, and maximum dynamic pressure of $800 \mathrm{lbf} / \mathrm{ft}^{2}$. Fuel capacity is $57000 \mathrm{lbf}$, and there are 10 tanks.

The range of the aircraft is $2500 \mathrm{n} \mathrm{mi}$, the maximum cruise altitude is $4000 \mathrm{ft}$, and the maximum operating Mach number is 0.843 . The ramp weight is $250000 \mathrm{lbf}$. Maximum allowed takeoff and landing field length is $6000 \mathrm{ft}$. Maximum allowed approach velocity is $125 \mathrm{n} \mathrm{mi}$. Ground operations include a takeoff time of $0.4 \mathrm{~min}$, taxi in-andout time of $10 \mathrm{~min}$, and reserve holding time of $0.5 \mathrm{hr}$. 



\section{References}

${ }^{1}$ McCullers, L.A., “Aircraft Configuration Optimization Including Optimized Flight Profiles,” edited by Sobieski, J., Symposium on Recent Experiences in Multidisciplinary Analysis and Optimization, part 1, NASA CP-2327, 1984.

${ }^{2}$ Patnaik, S.N., Coroneos, R.M., Hopkins, D.A. and Lavelle, T.M., Lessons Learned During Solutions of Multidisciplinary Design Optimization Problems, AIAA, JA, Vol. 39, No. 3, 2002, pp. 386-393.

${ }^{3}$ Patnaik, S.N., Guptill, J.D., Hopkins, D.A., and Lavelle, T.M., "Neural Network and Regression Approximations in High Speed Civil Transport Aircraft Design Optimization,” NASA TM-206316, 1998.

${ }^{4}$ Patnaik, S.N., Guptill, J.D., Hopkins, D.A., and Lavelle, T.M., "Cascade Optimization for Aircraft Engines with Regression and Neural Network Analysis-Approximators,” AIAA JP, vol. 35, (1998), pp. 839-850.

${ }^{5}$ Guptill, J.D., Coroneos, R.M., Patnaik, S.N., Hopkins, D.A., and Berke, L., “CometBoards Users Manual: Release 1.0,” NASA TM-4537, 1996.

${ }^{6}$ Patnaik, S.N., Coroneos, R.M., Guptill, J.D., and Hopkins, D.A., "Comparative Evaluation of Different Optimization Algorithms for Structural Design Applications,” International Journal for Numerical Methods in Engineering, Vol. 39, 1996, pp. 1761-1774.

${ }^{7}$ Gendy, A.S., Patnaik, S.N., Hopkins, D.A., and Berke, L., "Optimization of Space Station Components Using Code CometBoards,” Comp. Meth. in Applied Mechanics and Engrg, vol. 129, (1996), pp. 133-149.

${ }^{8}$ Patnaik, S.N., Lavelle, T.M., Hopkins, D.A., and Coroneos, R.M., "Cascade Optimization Strategy for Aircraft and AirBreathing Propulsion System Concepts,” Journal of Aircraft, vol. 34, 1997, pp. 136-139.

${ }^{9}$ Patnaik, S.N., Lavelle, T.M., and Hopkins, D.A., “Optimization of Air-breathing Propulsion Engine Concept,” Int. Jnl. for Commun. in Num Methods in Engrg, vol. 13, (1977), pp. 635-641.

${ }^{10}$ Feagin, R.C., and Morrison, W.D., “Delta Method, An Empirical Drag Buildup Technique,” NASA CR-151971, 1978.

${ }^{11}$ Sommer, S.C., and Short, B.J., "Free-Flight Measurements of Turbulent-Boundary-Layer Skin Friction in the Presence of Severe Aerodynamic Heating at Mach Numbers from 2.8 to 7.0,” NACA TN-3391, 1955.

${ }^{12}$ Geiselhart, K.A., "A Technique for Integrating Engine Cycle and Aircraft Configuration Optimization," NASA CR-191602, 1994.

${ }^{13}$ Geiselhart, K.A., Caddy, M.J., and Morris, S.J., Jr., “Computer Program for Estimating Performance of Air-Breathing Aircraft Engines,” NASA TM-4254, 1991.

${ }^{14}$ Caddy, M.J., and Shapiro, S.R., “NEPCOMP-The Navy Engine Performance Computer Program, Version I,” NADC74045-30, 1975

${ }^{15}$ Clark, B.J., “Computer Program To Predict Aircraft Noise Levels,” NASA TP-1913, 1981.

${ }^{16}$ Johnson, V.S., "Life Cycle Cost in the Conceptual Design of Subsonic Commercial Aircraft,” Ph.D. Thesis, Univ. of Kansas, Lawrence, KS, 1989.

${ }^{17}$ Eide, D.G., “Cost Estimating Relationships for Airframes in the Development and Production Phases,” NASA TM-80229, 1980.

${ }^{18}$ Beltramo, M.N., Trapp, D.L., Kimoto, B.W., and Marsh, D.P., "Parametric Study of Transport Aircraft Systems Cost and Weight,” NASA CR-151970, 1977.

${ }^{19}$ Nelson, J.R., and Timson F.S., "Relating Technology to Acquisition Costs: Aircraft Turbine Engines,” R-1288-R, Rand Corp., Santa Monica, CA, 1974.

20“A New Method for Estimating Current and Future Transport Aircraft Operating Economics,” American Airlines, NASA CR-145190 (rev.), 1978.

${ }^{21}$ Stoessel, R.F., “A Proposed Standard Method for Estimating Airline Indirect Operating Expenses,” CN-150, Logistic Distro-Data, Inc., 1970.

${ }^{22}$ Patnaik, S.N., Guptill, J.D., and Berke, L., "Merits and Limitations of Optimality Criteria Method for Structural Optimization,” International Journal for Numerical Methods in Engineering, vol. 38, 1995, pp. 3087-3120.

23،"DOT User’s Manual, Version 2.00,” Engineering Design Optimization, Inc., Santa Barbara, CA, 1989.

${ }^{24}$ Belegundu, A.D., Berke, L., and Patnaik, S.N., “An Optimization Algorithm Based on the Method of Feasible Directions,” Structural Optimization, vol. 9, 1995, pp. 83-88.

${ }^{25}$ Schittkowski, K., “User’s Manual, FORTRAN Subroutines for Mathematical Applications, Version 2.0,” IMSL, Inc., Houston, TX, 1991.

${ }^{26}$ Arora, J.S., “IDESIGN User’s Manual Version 3.5.2,” Optimal Design Laboratory, The University of Iowa, Iowa City, IA, 1989.

27“NAG FORTRAN Library Manual-MARK 15,” NAG FORTRAN Library Routine Document, Downer’s Grove, IL, 1991.

${ }^{28}$ Miura, H., and Schmit, L.A., Jr., "NEWSUMT-A FORTRAN Program for Inequality Constrained Function Minimization, Users Guide,” NASA CR-159070, 1979.

${ }^{29}$ Gabriele, G.A., and Ragsdell, K.M., "OPT-A Nonlinear Programming Code in FORTRAN Implementing the Generalized Reduced Gradient Method, User’s Manual,” University of Missouri-Columbia, 1984.

30"RPK_NASTRAN,” COSMIC, University of Georgia, Athens, GA, 1994.

${ }^{31}$ Nakazawa, S., “MHOST Version 4.2. Vol. 1: User’s Manual,” NASA CR-182235, 1989.

${ }^{32}$ Venkayya, V.B., and Tischler, V.A., “ANALYZE: Analysis of Aerospace Structures with Membrane Elements,” Report AFDL-TR-78-170, Air Force Flight Dynamics Laboratory, Wright-Patterson Air Force Base, OH, 1978. 
${ }^{33}$ Patnaik, S.N., Hopkins, D.A., Aiello, R.A., and Berke, L., “Improved Accuracy for Finite Element Structural Analysis via a New Integrated Force Method,” NASA TP-3204, 1992.

${ }^{34}$ Plencner, R.M., and Snyder, C.A., “The Navy/NASA Engine Program (NNEP89)—A User's Manual,” NASA TM-105186, 1991.

${ }^{35}$ Gendy, A.S., Patnaik, S.N., Hopkins, D.A., and Berke, L., "Parallel Computational Environment for Substructure Optimization,” NASA TM-4680, 1995.

${ }^{36}$ Hafez, W.A., “Cometnet-User Manual,” IntelliSys, Beachwood, OH, 1996.

${ }^{37}$ Anderson, E., et al., “LAPACK User’s Guide,” Society for Industrial and Applied Mathematics, Philadelphia, PA, 1992.

${ }^{38}$ Press, W., Teukolsky, S., Vetterling, W., and Flannery, B, “Numerical Recipes Example Book (C),” Cambridge University Press, NY, 1987. 
Public reporting burden for this collection of information is estimated to average 1 hour per response, including the time for reviewing instructions, searching existing data sources, gathering and maintaining the data needed, and completing and reviewing the collection of information. Send comments regarding this burden estimate or any other aspect of this collection of information, including suggestions for reducing this burden, to Washington Headquarters Services, Directorate for Information Operations and Reports, 1215 Jefferson Davis Highway, Suite 1204, Arlington, VA 22202-4302, and to the Office of Management and Budget, Paperwork Reduction Project (0704-0188), Washington, DC 20503.

\begin{tabular}{|l|c|c|}
\hline 1. AGENCY USE ONLY (Leave blank) & $\begin{array}{c}\text { 2. REPORT DATE } \\
\text { August 2004 }\end{array}$ & $\begin{array}{c}\text { 3. REPORT TYPE AND DATES COVERED } \\
\text { Technical Memorand }\end{array}$
\end{tabular}

4. TITLE AND SUBTITLE

A Subsonic Aircraft Design Optimization With Neural Network and Regression Approximators

6. AUTHOR(S)

WBS-22-708-24-05

Surya N. Patnaik, Rula M. Coroneos, James D. Guptill, Dale A. Hopkins, and William J. Haller

\section{PERFORMING ORGANIZATION NAME(S) AND ADDRESS(ES)}

National Aeronautics and Space Administration

John H. Glenn Research Center at Lewis Field

Cleveland, Ohio 44135-3191

8. PERFORMING ORGANIZATION REPORT NUMBER

E-14504

\section{SPONSORING/MONITORING AGENCY NAME(S) AND ADDRESS(ES)}

National Aeronautics and Space Administration

Washington, DC 20546-0001

10. SPONSORING/MONITORING AGENCY REPORT NUMBER

NASA TM-2004-213059

AIAA-2004-4606

\section{SUPPLEMENTARY NOTES}

Prepared for the 10th Multidisciplinary Analysis and Optimization Conference cosponsored by the American Institute of Aeronautics and Astronautics and the International Society for Structural and Multidisciplinary Optimization, Albany, New York, August 30September 1, 2004. Surya N. Patnaik, Ohio Aerospace Institute, Brook Park, Ohio 44142 and NASA Resident Research Associate at Glenn Research Center; and Rula M. Coroneos, James D. Guptill, Dale A. Hopkins, and William J. Haller, NASA Glenn Research Center. Responsible person, Surya N. Patnaik, organization code 5930, 216-433-5916.

12a. DISTRIBUTION/AVAILABILITY STATEMENT 12b. DISTRIBUTION CODE

Unclassified - Unlimited

Subject Category: 05

Distribution: Nonstandard

Available electronically at http://gltrs.grc.nasa.gov

This publication is available from the NASA Center for AeroSpace Information, 301-621-0390.

\section{ABSTRACT (Maximum 200 words)}

The Flight-Optimization-System (FLOPS) code encountered difficulty in analyzing a subsonic aircraft. The limitation made the design optimization problematic. The deficiencies have been alleviated through use of neural network and regression approximations. The insight gained from using the approximators is discussed in this paper. The FLOPS code is reviewed. Analysis models are developed and validated for each approximator. The regression method appears to hug the data points, while the neural network approximation follows a mean path. For an analysis cycle, the approximate model required milliseconds of central processing unit (CPU) time versus seconds by the FLOPS code. Performance of the approximators was satisfactory for aircraft analysis. A design optimization capability has been created by coupling the derived analyzers to the optimization test bed CometBoards. The approximators were efficient reanalysis tools in the aircraft design optimization. Instability encountered in the FLOPS analyzer was eliminated. The convergence characteristics were improved for the design optimization. The CPU time required to calculate the optimum solution, measured in hours with the FLOPS code was reduced to minutes with the neural network approximation and to seconds with the regression method. Generation of the approximators required the manipulation of a very large quantity of data. Design sensitivity with respect to the bounds of aircraft constraints is easily generated.

\section{SUBJECT TERMS}

Subsonic aircraft; Design optimization; Regression method; Neural network; FLOPS; CometBoards

17. SECURITY CLASSIFICATION OF REPORT

Unclassified

\section{SECURITY CLASSIFICATION OF THIS PAGE \\ Unclassified}

19. SECURITY CLASSIFICATION OF ABSTRACT

Unclassified
15. NUMBER OF PAGES

16

16. PRICE CODE 20. LIMITATION OF ABSTRACT 

